\title{
Glass and Glass-ceramics based on Weathered Basaltic Rock for Radiation Shielding Applications
}

\section{Gamal khater}

NRC: National Research Centre

heba saudi

Al-Azhar University

wesam Abd-Allah ( $\square$ wesamomar2007@yahoo.com )

National Center of Radiation Research \& Technology Atomic Energy Authority https://orcid.org/00000003-4745-4344

\section{Research Article}

Keywords: Gamma-ray, Shielding, basalt, Mass attenuation coefficient, Half-value layer, Effective atomic number

Posted Date: July 29th, 2021

DOI: https://doi.org/10.21203/rs.3.rs-749125/v1

License: (c) (1) This work is licensed under a Creative Commons Attribution 4.0 International License. Read Full License 


\title{
Glass and glass-ceramics based on weathered basaltic rock for radiation shielding applications
}

\section{G.A. Khater ${ }^{\text {a }}$, H. A. Saudi ${ }^{\text {b }}$ W.M.Abd-Allah}

${ }^{a}$ Glass Research Department, National Research Centre, Dokki, Cairo, Egypt

b Department of Physics, Faculty of Science (Girls' Branch), Al-Azhar University, Cairo, Egypt.

${ }^{\mathrm{c}}$ Radiation Chemistry. Department, National Centre for Radiation Research and Technology (NCRRT), Egyptian Atomic Energy Authority, Egypt

\begin{abstract}
Different batches of weathered basalt ranging from 100 to $50 \%$, in combination with by-pass cement dust, were used to prepare the glass compositions. Different techniques used, such as differential thermal analysis, X-ray diffraction, density, FTIR, the mass attenuation coefficients, appropriate atomic number (Zeff), and effective electron density (Neff), were examined for the prepared glass and glass-ceramics samples at different photon energies.. In the present study, it was revealed that as the molar volume decreases, the density increases. The experimental and theoretical effects of the mass attenuation component were mostly consistent at different energies. Results revealed that glass samples (WB100) having a higher percentage of basaltic rocks present higher radiation protection than those with a lower rate (WB50). In addition, glass-ceramics displayed enhanced radiation and gamma rays protection than glass. Therefore, we recommend using glass ceramics containing $100 \%$ Basalt as a protective shield against rays with less thickness and higher protection.
\end{abstract}

Keywords: Gamma-ray, Shielding, basalt, Mass attenuation coefficient, Half-value layer, Effective atomic number.

*Corresponding Authors: Emails: wesamomar2007@yahoo.com

\section{Introduction:}

Nuclear technologies apply to many industries: laboratory-scale medical physics and nuclear research. For example, insect control with sterile insect technology, gene mutation of plants and preservation of foodstuff in the food industry, radiotherapy in the medicine field, radiography in the non-destructive testing field, structural characterization of materials in the radiation protection field and radiation dosage dosing, etc., Known as radiation applications (1).

Radiation shielding is a common problem that has received much attention so far. In various radiation technologies and applications, the interaction of energetic $\mathrm{X} / \gamma$ ray radiation and a neutron with the material is 
essential. (2). The advantage of ceramic glass is its fine-grained crystalline texture formed by the glass heat treatment [3].

Only specific glass composition can be appropriate precursors for glassceramics productions, although some glasses are very stable, such as ordinary window glass, and challenging to crystallize. Most glass-ceramic materials contain a high percentage of crystalline materials, ranging from 50 to 95 percent, and the rest are residual glass [4].

Glass-ceramic materials have a range of excellent compositional properties that make them suitable for corrosion-resistant applications in applied manufacturing, electronics, and other areas.

From the traditional method of making glass-ceramics of pure chemicals, which raises the cost of the manufactured products, this article focuses on preparing glass-ceramics from weathered basalt and industrial wastes, which can be used in various ways to improve the economic state.(3).

Basalt is an extensive magmatic rock that forms 95 percent of continental and oceanic lava and pyroxene andesite. It is dark, almost black microlithic (generally containing only small amounts of glass) and is composed essentially of feldspar, plagioclase, and ferromagnesian minerals (mainly augite); accessory minerals are olivine, apatite, and magnetite. Khater et al. have succeeded in using basalt rocks with industrial waste to obtain a high-performance ceramic glass that can be used for construction purposes $(4 ; 5)$.

During the manufacturing of cement and iron, waste materials such as bypass cement dust and iron slag are produced. If these large amounts of industrial waste are not adequately treated, they will cause significant environmental and ecological issues, so their use is deemed profitable [8]. Cement processing is one of the most polluting sectors, according to the Central Pollution Control Board (CPCB)(6). The cement kiln by-pass dust is a hazardous waste material coming from the manufacture of P. C. clinker, and it is considered one of the leading direct reasons for air pollution, especially in the dwelling zone near or close to the cement factories. As this dust is positively loaded with chlorine and alkaline, this dust in the cement mills is limited. Furthermore, this dust disposal quite expensive due to the high chlorine content, and it is often categorized as hazardous waste.

Several types of glasses have piqued scientists' interest in the past few decades for use as alternative shield materials in a variety of nuclear applications due to a variety of intriguing physical properties such as good light transparency, ease of preparation, composition stability, density when exposed to an external field, and, most importantly, their ability to absorb high-energy photons.(7-12).

The studied wastes used for the prepared glasses are known to consist of alkali and alkaline earth ions, especially $\mathrm{Ca}^{2+}$ or $\mathrm{Mg}^{2+}$ ) occupy interstices or holes within the networks in the same time presences of alkali and alkaline earth 
oxides of sodium and calcium, which play an essential role in increasing NBO in the glass (13).

The addition of various ions to the glass will modify the density based on where these ions are housed in the network structure; the results obtained can be described by considering the glass system analyzed and cations added in the glassy network. When considering the glass structure under investigation and the form of cations inserted into the glassy network (14).

Glass batches have a high percentage of monovalent and divalent metals are applied to silica, single-bonded or non-bridging oxygen atoms are formed, meaning oxygen is bound to just one silicon atom in alkali silicate glasses. The sodium ions are attached to the underlying oxygens by bonds that are much more ionic and weaker than the silicon-oxygen bonds, or the WB structure, mainly made up of silicon, calcium, and aluminum oxides be used to explain this. The presence of $\mathrm{AlO}_{3}$ in the form of $\mathrm{SiO}_{4}$ tetrahedra $\mathrm{AlO}_{4}$ groups around divalent cations makes them more stable than similar groups found around monovalent cations. As a result, the structure is expected to form a series of more or less regular interstices around the $\mathrm{Ca}^{2+}$ and $\mathrm{Mg}^{2+}$ cations, with a proportion of large irregular interstices containing $\mathrm{Na}+$ ions, most likely with several $\mathrm{Na}^{+}$ions in each of the large, irregular rings. As a result, sodium ions are only marginally maintained in the system, with divalent cations taking up most of the more frequent interstices(15).

The aim of this study is the possibility of using weathered basalt and bypass cement dust to produce materials made of glass-ceramic that can be used in radiation shielding applications

\section{Methodology}

\subsection{Batch calculation and glass preparation}

Table 1 gives the chemical analysis of the raw materials used in preparing glass samples. Six glass samples based on weathered basalt and cement dust were designed and named WB100-WB50 (Table 2). These batches were well mixed and melted in platinum crucibles in an electric furnace at temperatures ranging from 1350 to $1400{ }^{\circ} \mathrm{C}$. The melt was stirred every half hour until the sample became utterly homogeneous, and then poured in the hot-plate form of discs and rods. Next, the model was transferred directly into the annealing furnace at a temperature of $550{ }^{\circ} \mathrm{C}$ for two $\mathrm{h}$ to release the thermal stress, keep via gradual cooling. Then, the prepared mother glasses were heat-treated at the required temperatures according to DTA results to obtain glass-ceramic materials.

\subsection{Differential Thermal Analysis}

DTA measurements were presented via DTG60 (Shimadzu, Japan) using $30 \mathrm{mg}$ of powdered glass samples with has a grain size of fewer than 60 microns, the powdered glass samples placed in platinum crucibles and heated from room temperature to $1000^{\circ} \mathrm{C}$ with a heating rate of $10^{\circ} \mathrm{C} / \mathrm{min}$. At the same time, $\mathrm{A} 12 \mathrm{O} 3$ powder was used as reference material. 


\subsection{X-ray Diffraction}

An X-ray diffraction analysis device was used to find out the crystalline phases formed during the crystallization process. X-ray diffraction used a Bruker D8 (Germany) adopting $\mathrm{Cu}$ radiation with $\mathrm{Ni}$-filter at a speed of $2^{\circ} 2 \Theta / \mathrm{min}$. The reference data of the interpretation of X-ray were obtained from American Standard for Testing Materials (ASTM) [16 \& 17]

The formula below can be used to measure density values for prepared samples, which is based on the Archimedes principle.;

\section{$\rho=(a / a-b) \times 0.86 \mathrm{~g} / \mathrm{cm}^{3}$}

The glass weights in air and xylene are $a$ and $b$, respectively, and the density of xylene at $20^{\circ} \mathrm{C}$ is 0.86 . To ensure that the measurement was correct, the experiment was repeated three times.

The molar volume can evaluate as $\boldsymbol{V}_{m}=\frac{\boldsymbol{M}}{\boldsymbol{\rho}}$

where $\mathrm{M}$ the molar weight of the glass. The oxygen packing density the formula was calculated: where $M$ is the molecular weight of each sample of glass and $\mathrm{C}$ is the number of oxygen atoms per unit of the formula.

\section{$\mathrm{OPD}=(1000 * \mathrm{C} * \rho) / \mathrm{M} \quad \mathrm{g}$ atom/l-------(3)}

A Fourier Transform infrared spectrometer was used to test the FTIR absorption spectra of the glass samples at room temperature in the wavelength range $400-4000 \mathrm{~cm} 1$ (Thermo Nicolet 380 spectrometer).

The proposed glass system's attenuation coefficients were calculated in narrow beam transmission geometry with a $2 * 2 \mathrm{NaI}(\mathrm{TI})$ crystal detector with an energy resolution of 12.5 percent at $662 \mathrm{keV}$ and a multichannel analyzer (MCA). $131 \mathrm{Ba}, 60 \mathrm{Co}, 90 \mathrm{Th}$, and $137 \mathrm{Cs}$ are radioactive sources with varying photon energies. For each sample, incident and transmitted photon intensities were measured on MCA for a fixed preset period by selecting a narrow region symmetrical concerning the centroid of the image peak. The experimental setup is depicted schematically. As shown in Figure 1.

Linear attenuation coefficient (LAC) is the main shielding factor that describes the power of shielding material to reduce radiation intensity. The LAC is determined experimentally by means of Lambert Beers' law, as shown in equation (4)(16).

$\mu t=\ln \frac{I}{I O}$

The $\mu, t, I_{O}$, and I denote the LAC of the fabricated glass, the glass thickness, the incident, and transmitted gamma-ray intensity, respectively. The Half Value Layer (HVL) of the studied glass sample is the glass thickness required to reduce the intensity of gamma-ray photons to half of their initial value is calculated using equation (5)(9).

HVL $(\mathrm{cm})=\frac{\ln 2}{\mu}$

An effective atomic number Zeff can describe a multi-element sample in terms of its equivalent element. The Zeff for the examples can be 
determine through eq (6)

Zeff $=\frac{\sigma \mathrm{a}}{\sigma \mathrm{e}}$ (6)

Where

$\sigma \mathrm{a}=1 \backslash \mathrm{NA} \sum_{\mathrm{i}}^{\alpha}(\mathrm{fi} \mathrm{Ai}(\mu \mathrm{m}) \mathrm{i})$

$\sigma \mathrm{e}=\frac{1 \backslash \mathrm{NA} \sum_{\mathrm{i}}^{\alpha}(\mathrm{fi} \mathrm{Ai}(\mu \mathrm{m}) \mathrm{i})}{\mathrm{zi}}$

Equations 7 and $8 \sigma \mathrm{a}, \sigma \mathrm{e}, \mathrm{fi}, \mathrm{Ai}$, and zi are the atomic cross-sections, electric cross-section, fractional abundance, mass number, and an atomic number of the ith content of samples.

\section{Results and discussion}

\subsection{DTA}

The DTA of the investigated glasses (Fig.2) shows a tiny dip between 718 to $740^{\circ} \mathrm{C}$, which agrees to the glass change temperature ( $\mathrm{Tg}$ ). It was found that $\mathrm{Tg}$ decrease, with increasing of by-pass content from 10 to $50 \mathrm{wt} \%$. The major exothermic peaks in the temperature range of $821-915^{\circ} \mathrm{C}$, which agrees to the glass crystallization temperature $(\mathrm{Tc})$, Thermal parameters include the temperature of crystallization (Tc) and the temperature of glass transition ( $\mathrm{Tg}$ ). Glasses with a low by-pass cement content (WB100-WB70 samples) have a lower crystallization temperature, whereas glasses with a high by-pass cement content (WB60 \&WB50) have a rapid crystallization growth., Additionally, $\mathrm{SiO} 2$ decreases from 49.22 (WB100) to $35.34 \mathrm{wt} \%$ (WB50), while, in calcium oxide increase from 16.41 to $40.60 \mathrm{wt} \%$ in glasses WB100 to WB50, respectively. A release of thermal energy with consequent exothermic peaks is caused by glass devitrification. Glass samples rich in $\mathrm{SiO} 2, \mathrm{Fe} 2 \mathrm{O} 3$, and $\mathrm{Al} 2 \mathrm{O} 3$ (WB100-WB70) showed crystallization difficulty with resulted in broad exothermic peaks. Meanwhile, samples rich in by-pass $(\mathrm{CaO})$ (WB60 and WB50) displayed a faster crystallization rate with more defined exothermic peaks. The broad exothermic peaks from WB100 to WB70 reveal the large temperature choice overhead which crystallization can happen in these samples; however, the broad peak height to the prolonged times needed to achieve a fair amount of crystallization. WB60 and WB50 also exhibit exothermic peaks, representative of the progress of crystallization, a possibility that was confirmed through heat-treated temperature.

$\mathrm{SiO} 2, \mathrm{Al} 2 \mathrm{O} 3, \mathrm{Fe} 2 \mathrm{O} 3$ significantly change and decrease when the content of by-pass increases from zero to $50 \mathrm{wt} \%$. In contrast, $\mathrm{CaO}$ increases severely in glasses WB100 to WB50, correspondingly. Its value is revealing that the $\mathrm{Al}+3$ ion can't induce glass formation alone. Instead, it combines with another positively charged ion to reach electrical equilibrium and get into the building in the form of AlO4. Additionally, the combination of $\mathrm{Al} 3+$ and $\mathrm{Na}+$ reinforces the glass structure.

Increases in $\mathrm{CaO}$, on the other hand, increase the viscosity of the glass and, as a result, $\mathrm{Tg}$ significance The rise in $\mathrm{Tg}$ corresponds to the visually saw high 
viscosity in the studied samples with a higher by-pass percentage. The $\mathrm{Tg}$ values increase as the $\mathrm{Ca} 2+$ field strength increases; this result is reflected in a decrease in mobility, weakening the silica network, weakening the glass structure's stability. El-Shennawi et al. (17) presented that this endotherm shows the glass transition temperatures $(\mathrm{Tg})$ and is attributed to the change of the glass structure. Devekey (18) described this event of "preceding glass crystallization," in which the glass-early components start to arrange themselves at this degree, is correlated with this endotherm.

\subsection{XRD}

X-ray diffraction graphs (Fig.3) of the examined glasses WB100 WB50 after heat treatment at $1000^{\circ} \mathrm{C}$ for two hours show that the diopside (CaMgSi2O6) (ASTM. card no.11-654), wollastonite (CaSiO3) (JCPDS card no. 29-372), anorthite (CaAl2Si2O8) (ASTM. card no. 20-20), magnetite (Fe3O4) (ASTM. 19-629), hematite (Fe2O3) (JCPDS 33-664) are the main crystalline minerals grown in the present glass-ceramic materials. However, the amount of these phases varies based on the glass composition. In glass samples (WB100 to WB70), diopside (CaMgSi2O6), anorthite (CaAl2Si2O8), wollastonite $(\mathrm{CaSiO} 3)$, magnetite $(\mathrm{Fe} 3 \mathrm{O} 4)$, and hematite $(\mathrm{Fe} 2 \mathrm{O} 3)$ are the main crystalline phases (Fig.3). Where samples WB60 and WB50 (Fig.3) reveals that; galenite $(\mathrm{CaAl} 2 \mathrm{SiO} 7)$ is the primary crystalline phase with appearance lines; $3.72,2.85,2.43,2.04$, and $1.75 \AA$, the anorthite mineral disappeared, with the amounts of diopside, magnetite, and hematite decreased. The reduction of the Diopside phase is attributable to the decrease of $\mathrm{MgO}$ content in these investigated samples (Table 3); this element is responsible for forming the diopside mineral. That is why the diopside phase could not maintain the $\mathrm{Ca}$ Tschermak (CaAl2SiO6) of the inside of its lattice; additionally, increasing the ratio of $\mathrm{CaO}$ in cement dust and consequently, its increase in these samples facilitated the creation of gehlenite mineral as following.

$\mathrm{CaAl} 2 \mathrm{SiO} 6$ (in the lattice of diopsideplus $\mathrm{CaO}$ (additional from cement-dust samples WB60 and WB50) $\rightarrow \mathrm{Ca} 2 \mathrm{Al} 2 \mathrm{SiO} 7$ (gehlenite main phase) plus the small intensity of diopside lines (Fig.2). Concerning the vanishing of the anorthite phase, the reaction was as following; CaAl2Si2O8 (Anorthite) $\rightarrow \mathrm{Ca}$ Tschermak (CaAl2SiO6) $+\mathrm{SiO} 2$ (remaining glasses). The decrease of hematite and magnetite is due to the weathering process of samples WB60 \&WB50 that caused a reduction in the iron content (Table 3 ).

\subsection{Density and molar volume}

Fig 4 displays the density of the investigated glass and shows that the highest density is glass, as it contains $100 \%$ basalt. The presence of a high concentration of $\mathrm{Fe} 2 \mathrm{O} 3$ in basalt causes changes in the glass networks by filling the interstitial spaces, which become denser and heavier., as revealed in the results given in Table2, it is evident that the density increase that may be due to the formation of bridging oxygens that reduce the voids within the configuration(19). 
The molar volume also increases with an increase in By-pass cement, which indicates the expansion of the network and growth of $\mathrm{NBO}$ (non-bridging oxygens). This can be related to replacement Weathered Basalt(WB) by Bypass cement which has ions with a higher atomic radius such as Potassium and calcium existing in the By-pass cement. It can be understood in other claims that the large ionic radius contributes to an increase in distortion by increasing the number of NBO oxygen bridges to provide a more open structure with a large volume added, and then a decrease in density can take place(20).

OPD decreases by an increase in the concentration of By-pass cement in the glass network. Thus, it may be considered that replacement of By-pass cement leads to loose structure and a decrease of bridging oxygen in the glass system(21).

The oxygen packing density As the density decreases, Vm increases, while OPD decreases, meaning that the increase in the formation of NBO bonds in the glass structure(22).

\subsection{Interpretation of the FTIR spectra}

Figs (5 \&6)of FTIR charts are shown Present the absorbance as a wavenumber function where a peak is induced by each absorption process Molecular or chemical bond vibration, the peaks at $450-500 \mathrm{~cm}^{-1}$ can be related to bending modes of $\mathrm{Si}-\mathrm{O}-\mathrm{Si}$ or $\mathrm{O}-\mathrm{Si}-\mathrm{O}(23), 470 \mathrm{~cm}^{-1}$ due to the high concentration of $\mathrm{P} 2 \mathrm{O} 5$ and assigned to $\mathrm{O}-\mathrm{P}-\mathrm{O}$ and $\mathrm{P}-\mathrm{O}-\mathrm{Si}$ bonds(24). The one band at $570 \mathrm{~cm}^{-1}$ and can also be related to the vibrations of silicon-oxygen rings(25). The peak at $680 \mathrm{~cm}^{-1}$ is due to the beats of silicon-oxygen rings. The medium band at $720-780 \mathrm{~cm}^{-1}$ can be due to $\mathrm{Si}-\mathrm{O}-\mathrm{Si}$ symmetric stretching vibrations of bridging oxygens(BO) between tetrahedra(26). The band 1080 $\mathrm{cm}^{-1}$ symmetric stretching of $\mathrm{Si}-\mathrm{O}-\mathrm{Si}$ bonds. This band decreases in intensity when the $\mathrm{Al}_{2} \mathrm{O}_{3}$ quantity increases $(27 ; 28)$.

The infrared absorption bands at 1228 and $1291 \mathrm{~cm}^{-1}$ are related to the asymmetric stretching vibrations of the silicate tetrahedral network1620-1650 $\mathrm{cm}^{-1}$ is related to molecular water as shown in (Table 4). New information on changes to the glass matrix is difficult to extract, except tha t mentioned in the literature(29), which depends on the nature and/or quality of alkali oxide in silicateglasses, the deconvolution method is used to evaluate the established concentration ofsilicate structural units for the study of the infrared s pectra silicate glasses. Each spectrum was de-convoluted to individual peaks with Using Peak Fit v4.12 with R2 0.999 to give different vibrations to the silicate groups and suggest the center of the (C) band and the region (A) of the component band and the region below $\mathrm{SiO} 4$ units (30)which is given that the amount of areas involved under these peaks equals the whole area below the original area. Spectrum as in Fig. 6 for $\mathrm{x}=0 \mathrm{~mol} \%$. The band at $420-450 \mathrm{~cm}^{-1}$ correlates modifier cations in their residing sites as bridging and non-bridging types (e.g., $\mathrm{Na}^{+}, \mathrm{Ca}^{2+}$ ). This broadband reveals a peak at $920-980 \mathrm{~cm}^{-1}$ due to $\mathrm{Si}-\mathrm{O}-$ stretching with non-bridging oxygens $\mathrm{NBO}$, and $750-979 \mathrm{~cm}-1$ is due to 
the stretching vibrations of the $\mathrm{Al}-\mathrm{O}$ bonds with $\mathrm{Al}^{3+}$ ions in 4-fold coordination. By increasing the silica ratio, this peak shifts to higher wave numbers(31).

The most intense band at $1160 \mathrm{~cm}-1$ was related to the symmetric stretch mode of non-bridging oxygens (NBO) $\mathrm{V}_{\mathrm{s}}(\mathrm{PO} 2-)(32-34)$.

\subsection{The radiation shielding features}

Incident and transmitted intensities were determined with experimental confirmation of linear attenuation coefficients values of glass. Linear attenuation coefficients $(\mu)$ for glass were measured at photon energies of [0.082164] MeV. The results obtained are shown in Fig. 7. It can be seen that the measured results decrease with increasing thickness of the prepared glass and increase with increasing photon energies.

The values of the total mass attenuation coefficients $(\mu / \rho)$ are essential in many applications such as radiological physics and nuclear, radiation dosimetry, biological, medical, agricultural, environmental, and industrial. The half-value layer (HVL) is an essential parameter in order to test the shielding properties of the radiation of the material, and this is illustrated in Fig. 8, where it is shown as a function of the photon energy of glass based on weathered Basalt and cement wastes(35-38). Therefore, Fig. 8 confirms that a greater thickness of this glass is needed to stop the high-energy photons. The absorption of X-rays, scattering, and gamma rays are correlated to the density and atomic numbers of an element(39; 40). But as for glass, it is made up of a group of composite materials, so it has to do with the effective electron density ( $\mathrm{Ne})$ and the effective atomic number (Zeff).

Therefore a single number cannot uniquely signify the atomic number across the entire energy range, then the cross-sections of the partial reaction have a different atomic number; thus, we determine the adequate atomic number, Zeff, which is a very valuable parameter for many fields of scientific, technological and engineering applications. Zeff is a suitable parameter to signify the $\gamma$-ray attenuation in the medium. The mass attenuation coefficients $(\mu / \rho)$ of the current glass are plotted in Fig $9 . \mu / \rho$ depends on the energy of the photon and the concentration of weathered Basalt within the glass. From Fig 9, we conclude that the addition of basalt to by-pass cement affects mass attenuation coefficients $(20 ; 41)$. The experimental and theoretical values are in agreement to some extent.

The calculated Zeff, Ne, and Zeq of the current glass are also shown in Fig. 10,11, and 12. Changes in Zeff, Ne, and Zeq exhibit approximately similar behavior to $\mu / \rho$. The values for all of these are decrease because the absorption probability decreases with increasing energies of the incident photon. Ne and Zeq are closely associated with Zeff and have the exact specific energy requirement as Zeff since the three parameters are linked through $\mu / \rho$. Zeff, Zeq, and $\mathrm{Ne}$ results confirmed the ability to use this glass for shielding radiation. 


\subsection{Glass-ceramics:}

The values of density and mass attenuation obtained from glass-ceramics have relatively higher values than glass samples. Thus, all values of the previous gamma-ray protection. This is illustrated by Figures 13 and 14. The higher values of glass-ceramics are due to the inclusion of crystalline materials such as diopside, anorthite, magnetite, and hematite phases which increases the closely packed structure. Consequently, the crystalline phases increased the density, increased network cohesion, and increased absorption of gamma rays. From the previous results, it is evident that the glass structure is weaker than that of glass-ceramics; thus, the density and lower mass attenuation values of the glass samples can be taken as evidence of the amorphous nature and shortterm arrangement characteristics of glasses

Therefore, after all these results, we recommend using the glass-ceramics as a protective shield against gamma rays

\section{Conclusions}

In this study, glass and glass-ceramics based on weathered basalt and industrial wastes were prepared and examined in order to determine if they could be used as radiation shielding materials.

The density increases with an increase in by-pass cement, OPD decreases by the rise in the concentration of by-pass cement in the glass network. FTIR spectra current different molecular groups seemed after glass synthesis. The values of the mass attenuation coefficient ( $\mu / \rho)$, Zeff, and Neff improved. As photon energy increased, the quantity of weathered Basalt (WB) mol percent increased and decreased. Theoretical and experimental findings are consistent within $4 \%$ of the mass attenuation coefficient at different energies. According to the size required for the shield design and the values of the mass attenuation coefficient, glasses prepared from weathered basalt and cement wastes have the advantages of being from nature and re-using cement wastes to rid the environment from the resulting pollution and provide better protection from radiation compared to other materials. Glass-ceramic samples give a higher density and a more significant mass attenuation coefficient than glass samples. After reaching the results obtained from glass-ceramic samples and glass samples, it is recommended to use glass-ceramics as a protective shield from radiation, especially for the instance that contains a high percentage of weathered basalt (WB100).

Author contributions: The authors have equal contribution in the paper.

Acknowledgments: The authors thank the National Research Centre, National Center for Radiation Research and Technology, Egyptian Atomic Energy Authority (EAEA) for the possibility to use their equipment and facilities.

Availability of data and material: My manuscript and associated personal data will be shared with Research Square for the delivery of the author dashboard. 
Compliance with ethical standards: The manuscript has not been published elsewhere and has not been submitted simultaneously for publication elsewhere.

Conflict of interest: The authors declare that they have no conflict of interest.

Declaration of Competing Interest: The authors declare that they have no known competing financial interests or personal relationships that could have appeared to influence the work reported in this paper.

Funding statement: There are currently no Funding Sources on the list

Consent to participate: The authors consent to participate.

Consent for Publication: The author's consent for publication.

\section{References}

1. Kurudirek M, Chutithanapanon N, Laopaiboon R, Yenchai C, Bootjomchai C. 2018. Journal of Alloys and Compounds 745:355-64

2. Shamshad L, Rooh G, Limkitjaroenporn P, Srisittipokakun N, Chaiphaksa W, et al. 2017. Progress in Nuclear Energy 97:53-9

3. Khater G, Shehata M, Hamzawy E, Mahmoud M. 2017. Glass Technology-European Journal of Glass Science and Technology Part A 58:17-25

4. Khater G, Abdel-Motelib A, El Manawi A, Safiah MA. 2012. Journal of non-crystalline solids 358:1128-34

5. Khater G, Nabawy BS, Kang J, Yue Y, Mahmoud M. 2020. Silicon:1-20

6. Rawlings R, Wu J, Boccaccini A. 2006. Journal of materials science 41:733-61

7. Akman F, Kaçal M, Sayyed M, Karataş H. 2019. Journal of Alloys and Compounds 782:315-22

8. Saudi H. 2013. Applied Mathematics and Physics,(4) 1:143-6

9. Saudi H, Gomaa HM, Sayyed M, Kityk I. 2019. SN Applied Sciences 1:218

10. Issa SA, Tekin H, Erguzel T, Susoy G. 2019. Applied Physics A 125:1-16

11. El-Khayatt A, Saudy H. 2020. Radiation Physics and Chemistry 166:108497

12. Aygün B, Şakar E, Cinan E, Yorgun NY, Sayyed M, et al. 2020. Radiation Physics and Chemistry 174:108897

13. ElBatal H, Ghoneim N, Ouis M. Preparation and characterization of glass and glass-ceramics from industrial waste materials including iron slag and cement dust. Proc. Proceedings of the ICCM-17-17th International Conference on Composite Materials, Edinburgh, UK, 2009:27-31:

14. El-Badry KM, El-Batal H. 1973. Transactions of the Indian Ceramic Society 32:105-8

15. El-Alaily N, Abd-Elaziz T, Soliman L. 2018. Silicon 10:11-20

16. Issa SA, Sayyed M, Zaid M, Matori K. 2017. Journal of Spectroscopy 2017

17. El-Shennawi A, Morsi M, Khater G, Abdel-Hameed S. 1998. Journal of thermal analysis and calorimetry 51:553-60

18. De Vekey R, Majumdar A. 1970. Mineralogical Magazine 37:771-9

19. El-Alaily N, Abdallah W, Sabrah B, Saad A. 2017. Silicon 9:117-30

20. Shaaban KS, Abd-Allah W, Saddeek Y. 2020. Optical and Quantum Electronics 52:3

21. Arbuzov V, Carl G, Durschang B, Rüssel C. 1998. Journal of non-crystalline solids 231:125-33

22. Dogra M, Singh K, Kaur K, Anand V, Kaur P. 2017. Univers. J. Phys. App/ 11:190

23. Gervais F, Blin A, Massiot D, Coutures J, Chopinet M, Naudin F. 1987. Journal of noncrystalline solids 89:384-401

24. Yadav AK, Singh P. 2015. RSC advances 5:67583-609

25. Archidi M, Haddad M, Nadiri A, Benyaïch F, Berger R. 1996. Nuclear Instruments and Methods in Physics Research Section B: Beam Interactions with Materials and Atoms 116:145-9 
26. Aguiar H, Serra J, González P, León B. 2009. Journal of Non-Crystalline Solids 355:475-80

27. Bartholomew RF. 1972. Journal of Non-Crystalline Solids 7:221-35

28. Chatterjee M, Naskar MK. 2006. Ceramics international 32:623-32

29. Abd-Allah W, Nabhan E. 2018. Silicon 10:49-57

30. Yadav A, Gautam C. 2011. Lucknow Journal of Science 8:26-30

31. ElBatal HA, Hassaan MY, Fanny MA, Ibrahim MM. 2017. Silicon 9:511-7

32. Nabhan E, Abd-Allah W, Ezz-El-Din F. 2017. Results in Physics 7:119-25

33. Labbilta T, Mesnaoui M, Aouad H, Abouliatim Y, Khouloud M, Abielaala L. 2020. Materials 13:2637

34. Hussin R, Husin MS, Halim DNFA, Hamdan S. 2010. Adv. Mater. Res 18:288-301

35. Elkhoshkhany N, Khatab M, Kabary MA. 2018. Ceramics International 44:2789-96

36. Tekin H, Sayyed M, Issa SA. 2018. Radiation Physics and Chemistry 150:95-100

37. Issa SA, Saddeek YB, Sayyed M, Tekin H, Kilicoglu O. 2019. Composites Part B: Engineering 167:231-40

38. Saudi H, Abd-Allah W. 2020. Journal of Alloys and Compounds:158225

39. Abd-Allah WM, Saudi HA, Fahim RA. 2020. Journal of Inorganic and Organometallic Polymers and Materials 30:4311-9

40. Abd-Allah W, Saudi H, Shaaban KS, Farroh H. 2019. Applied Physics A 125:275

41. Saudi H, Abd-Allah W, Shaaban KS. 2020. Journal of Materials Science: Materials in Electronics 31:6963-76 
Figures

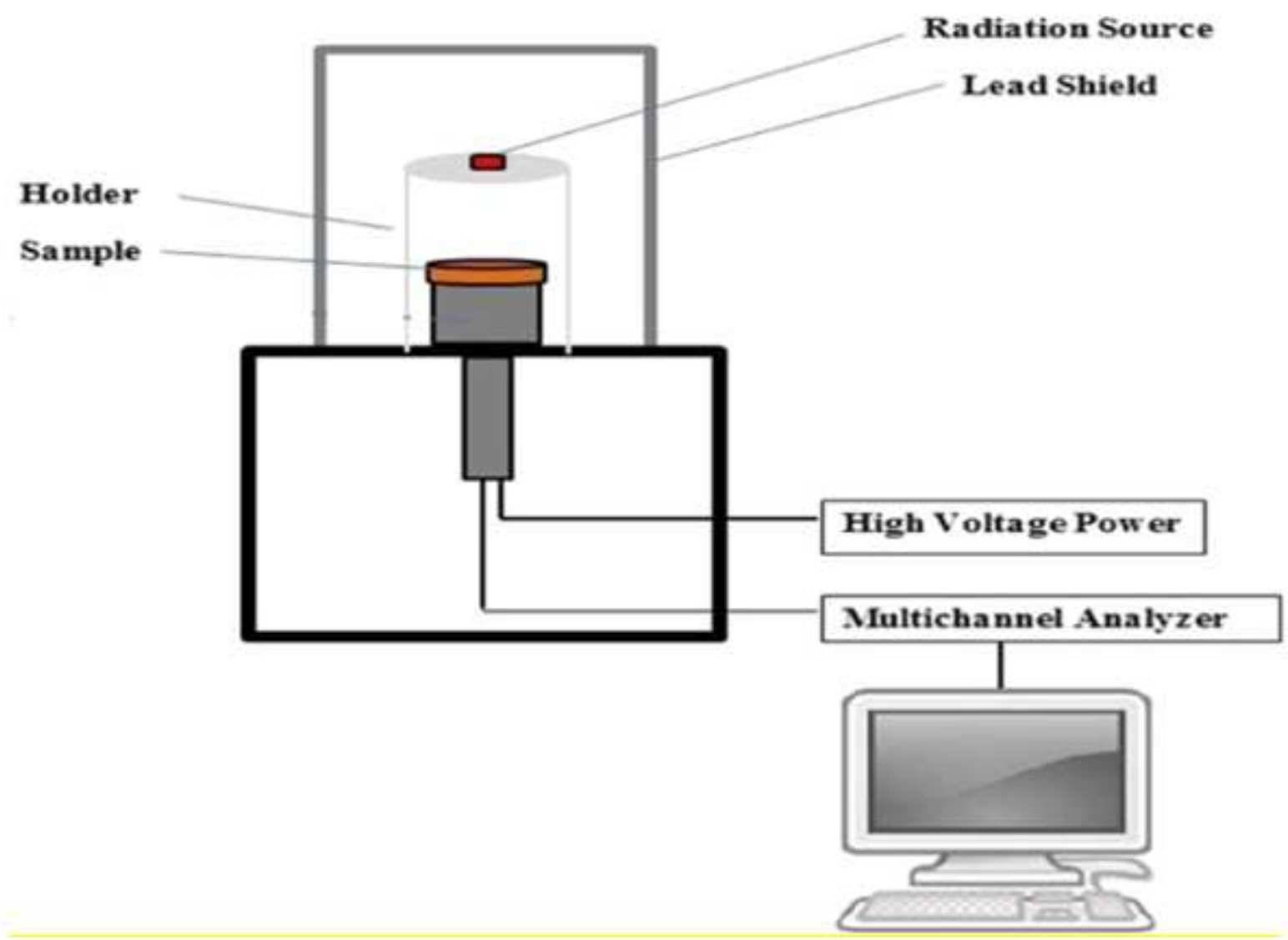

Figure 1

Experimental setup used to determine the linear attenuation coefficients. 


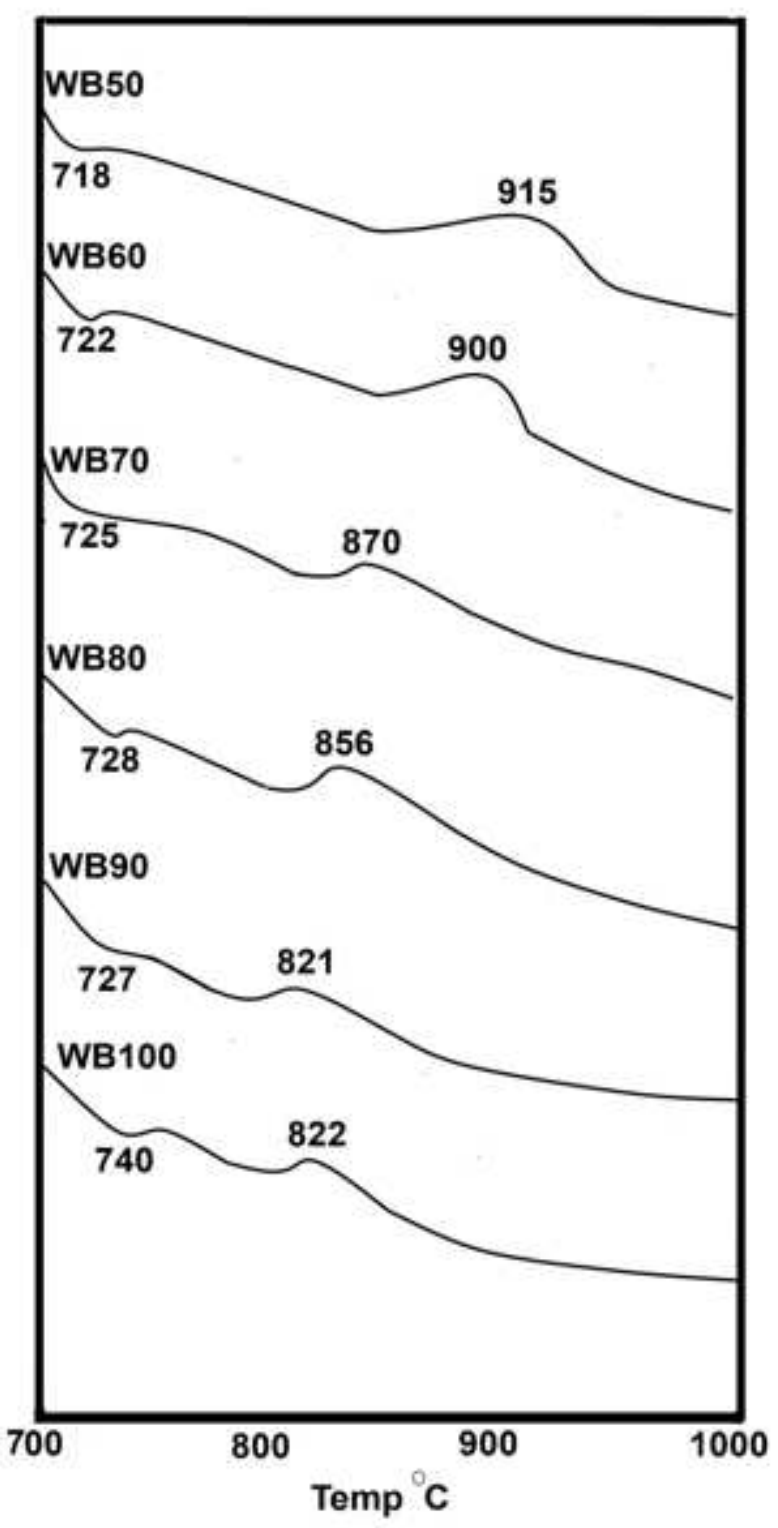

Figure 2

DTA of the investigated glass samples 


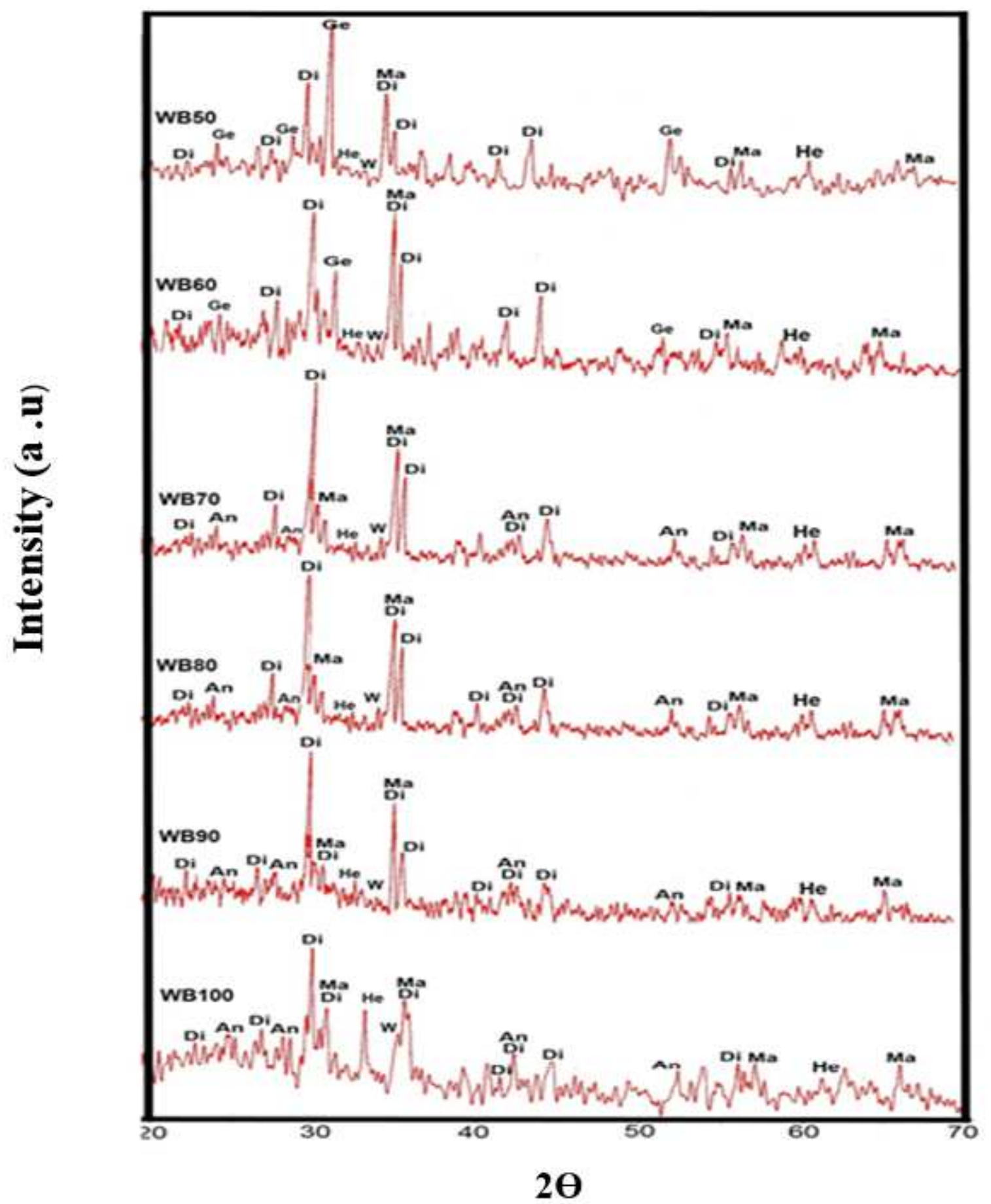

Figure 3

XRD of the investigated glass samples heat treated at $1000^{\circ} \mathrm{C}$ for $2 \mathrm{~h}$. Where: $\mathrm{Di}=$ Diopside, $\mathrm{An}=$ Anorthite, $\mathrm{Ge}=$ Gehlenite, $\mathrm{Ma}=$ Magnetite, $\mathrm{He}=$ Hematite, $\mathrm{W}=$ Wollastonite 


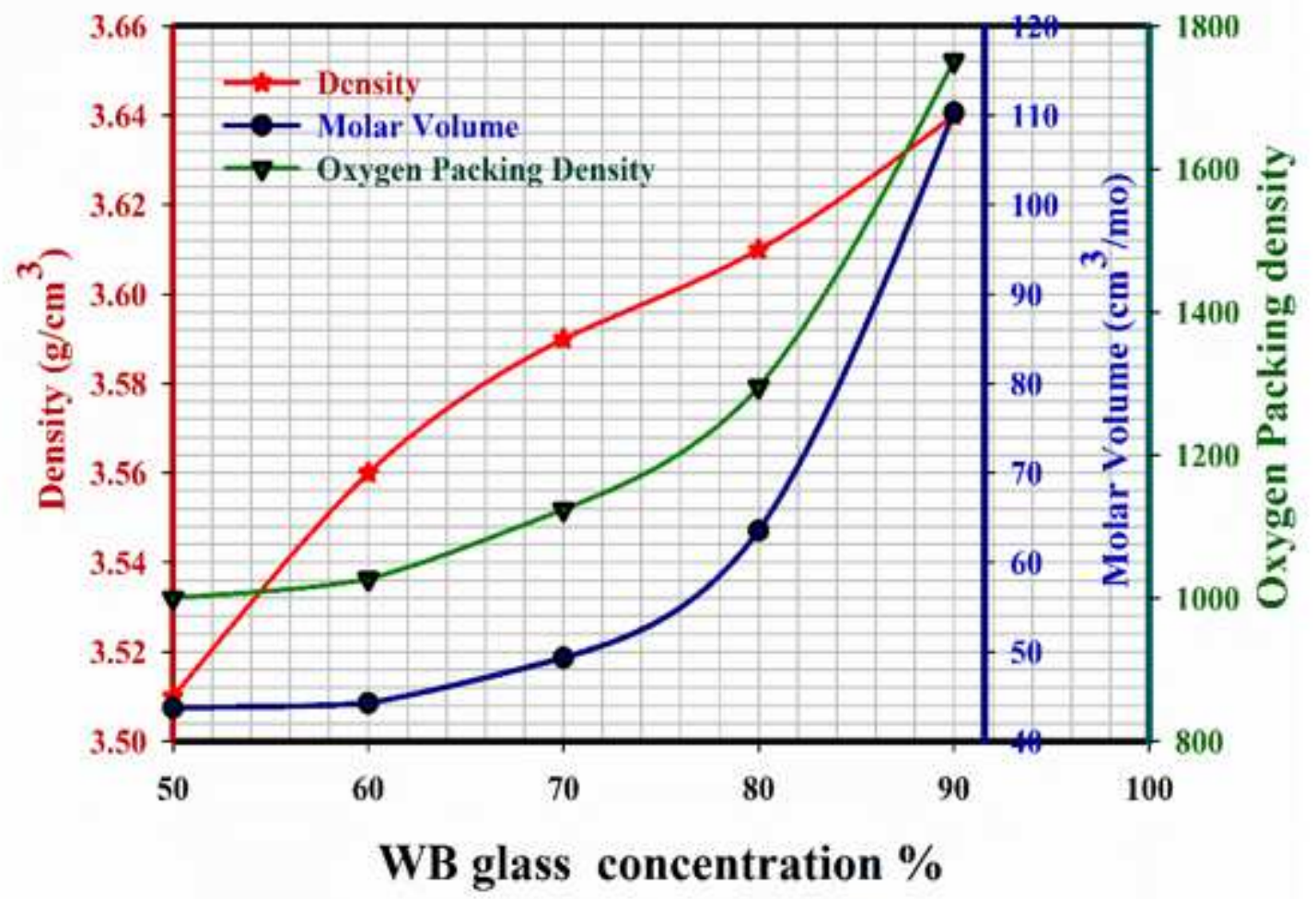

Figure 4

The values of density, Molar volume and OPD of glass samples system 


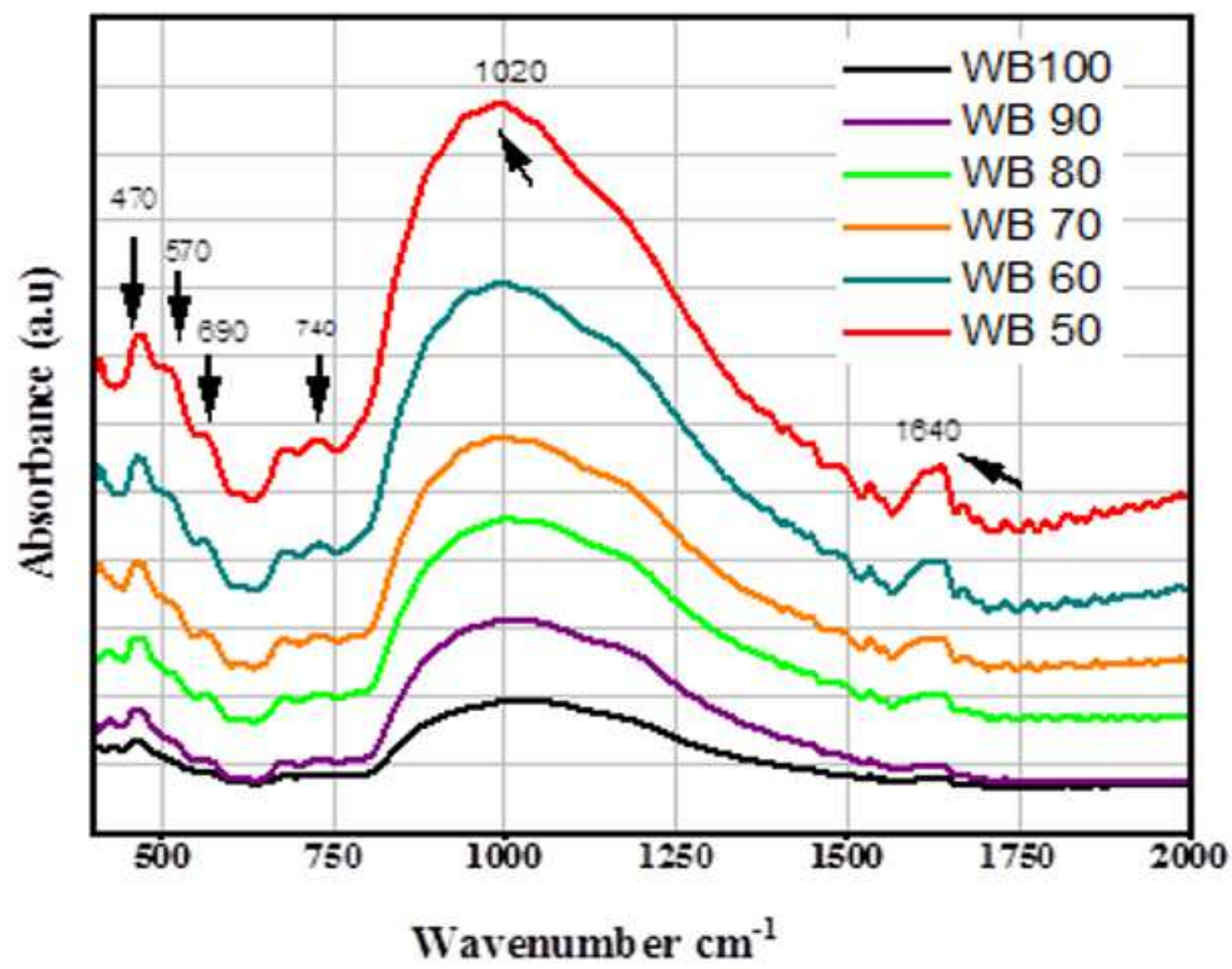

Figure 5

Infrared spectra of the investigated glasses

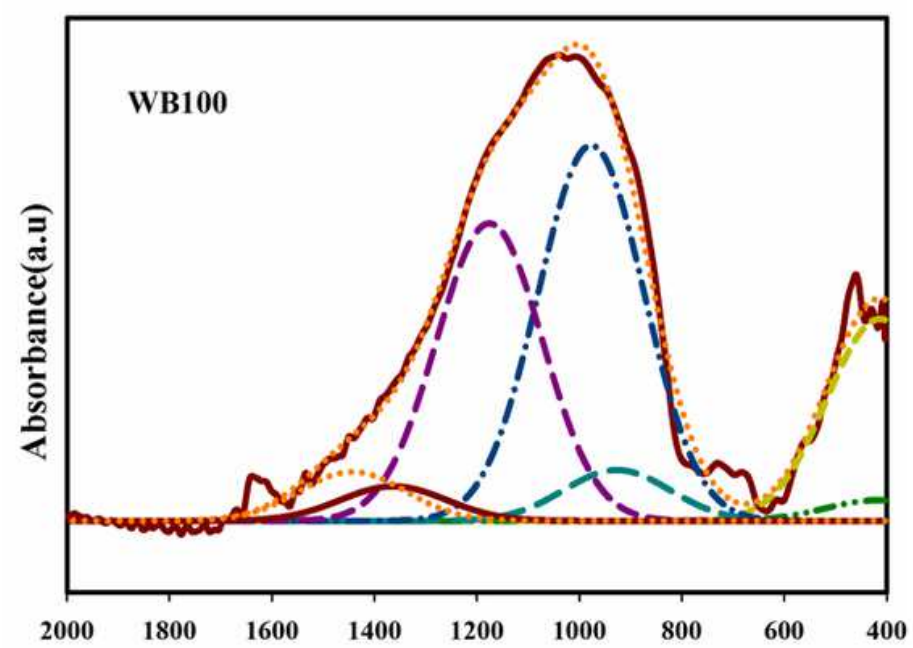

Wavenumber $\mathrm{cm}^{-1}$

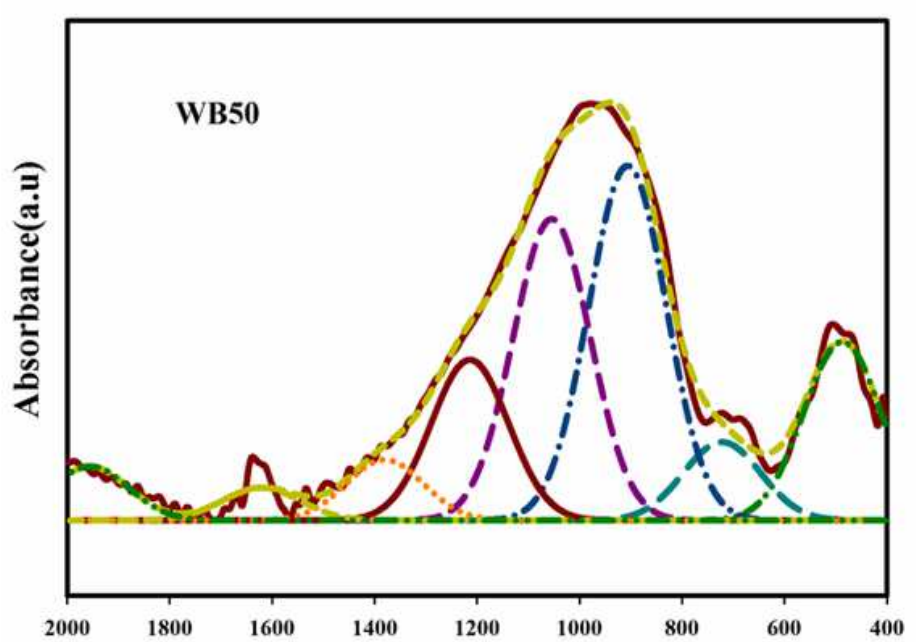

Wavenumber $\mathrm{cm}^{-1}$

Figure 6 


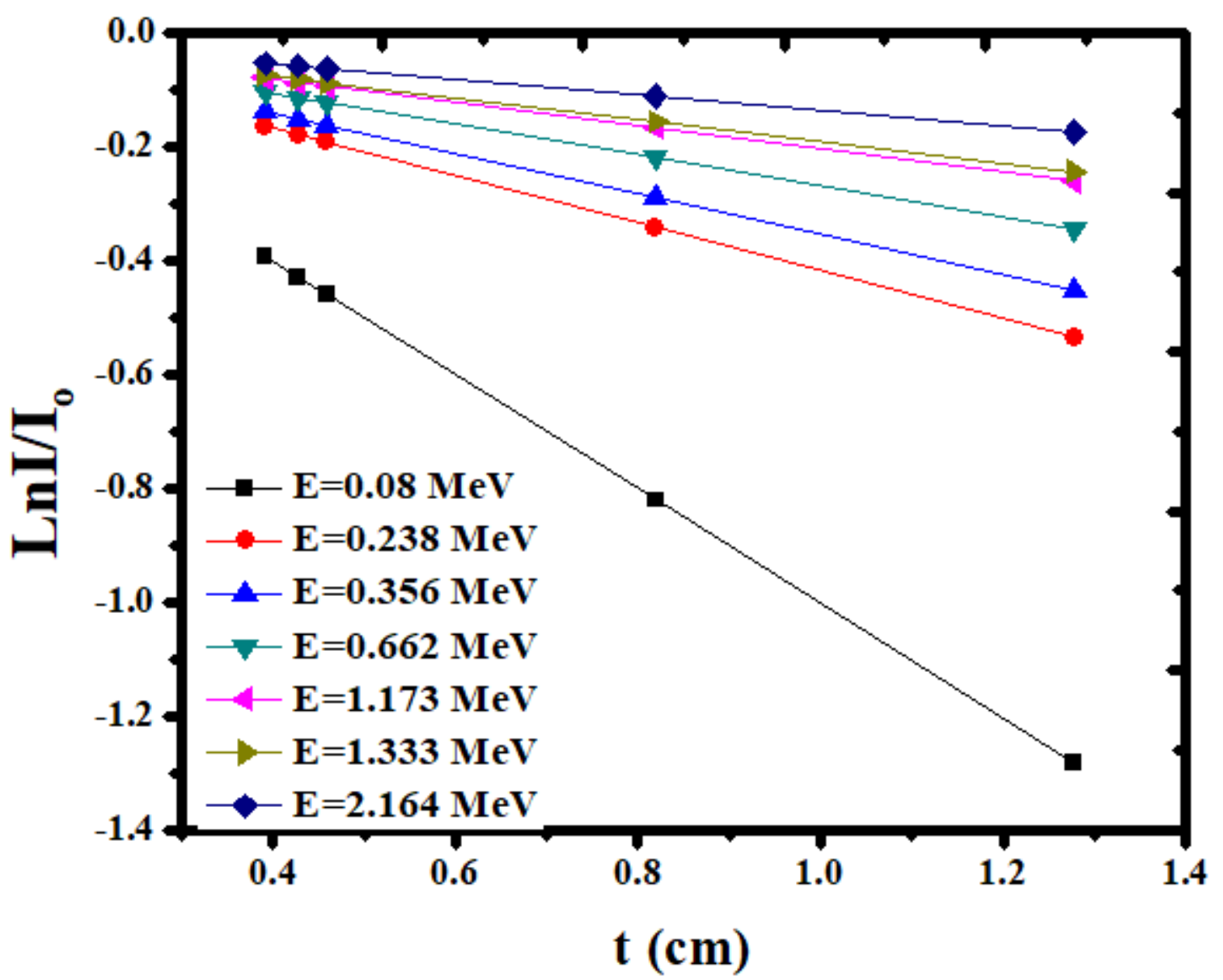

Figure 7

Linear attenuation coefficients ( $\mu$ ) for glass sample (WB60) as function of dfiffrent thickness at different photon enregies 


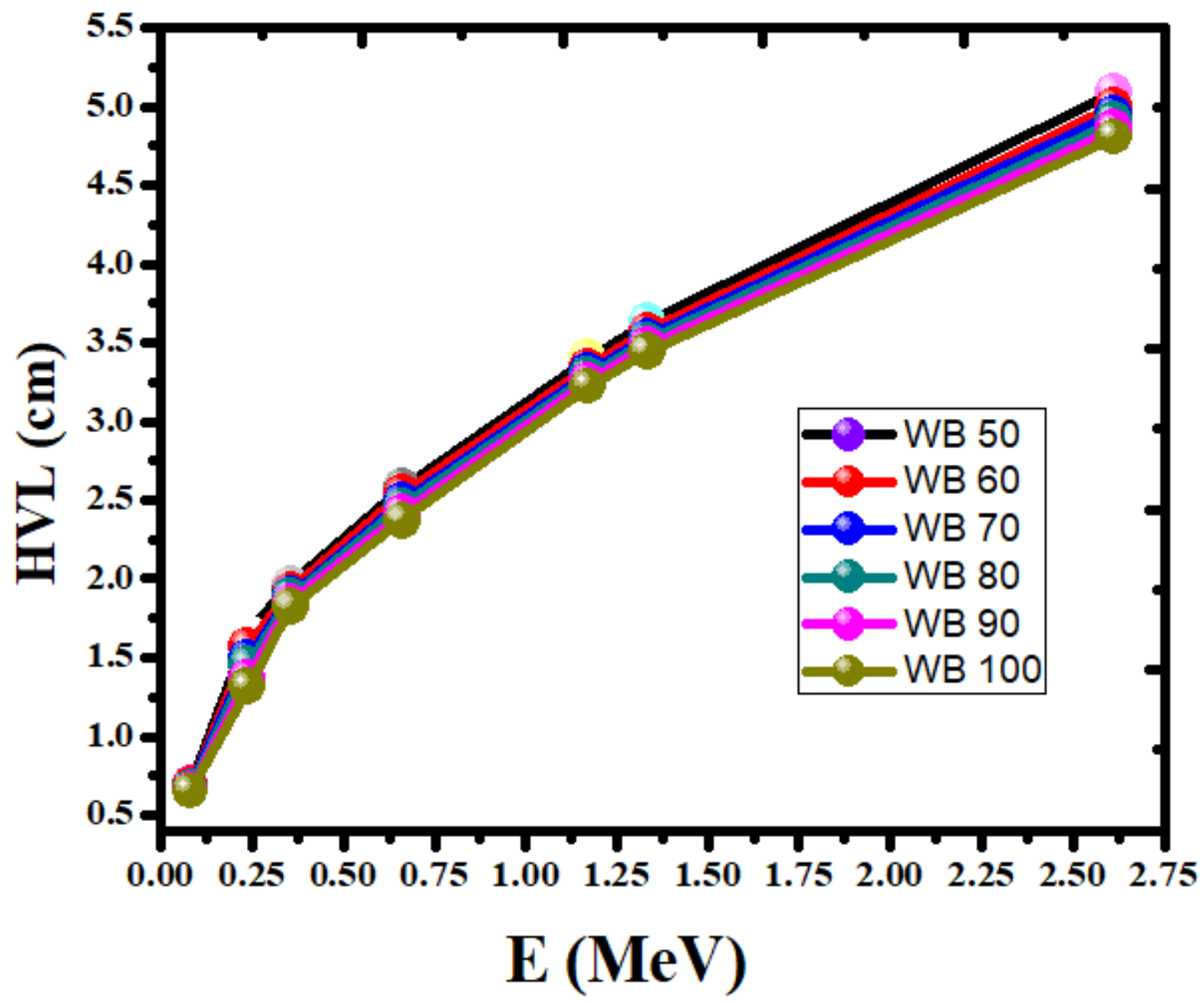

Figure 8

The half value layear (HVL) is a function of the photon energy 


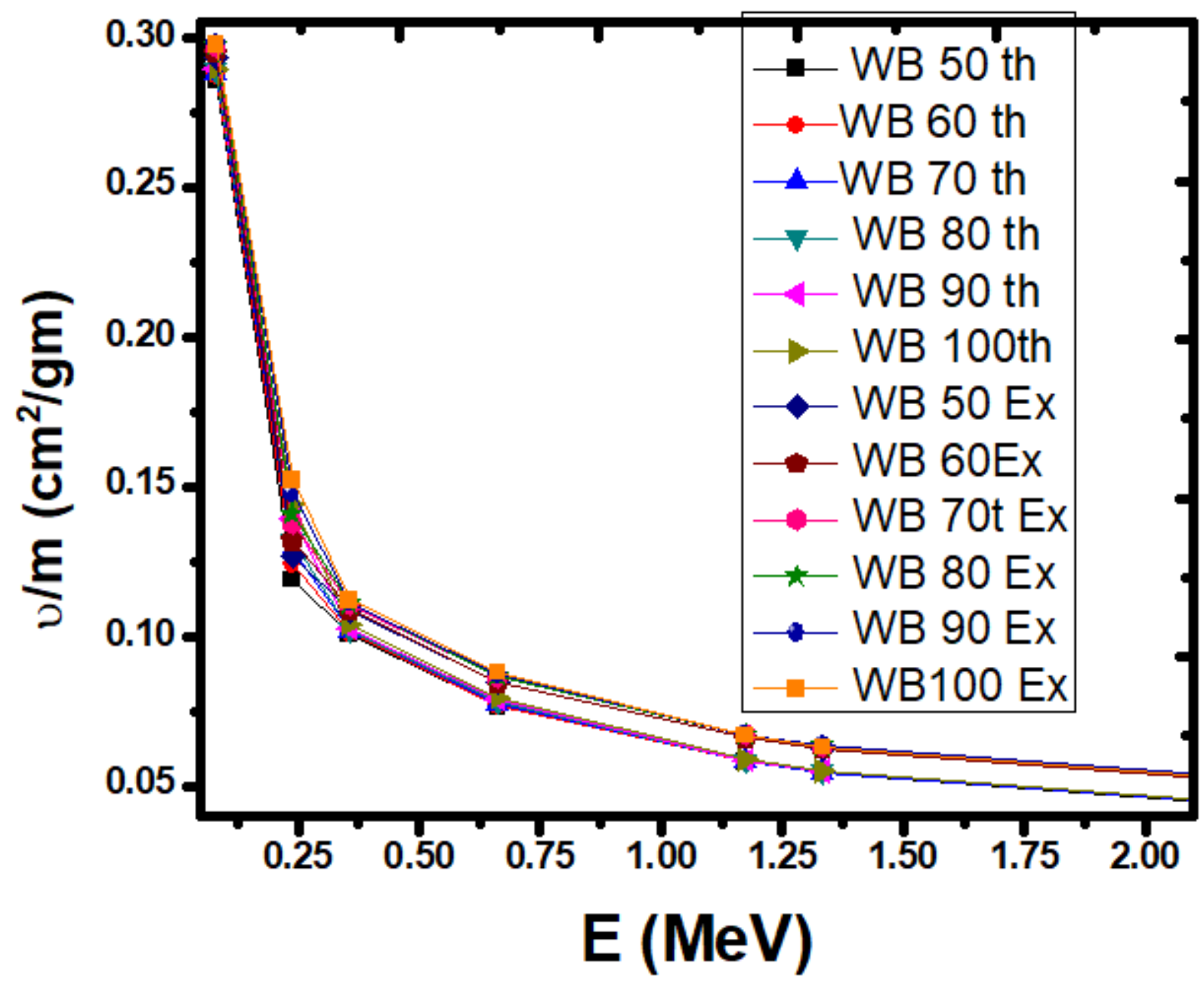

Figure 9

Experimentally measured results and theoretical (XCOM) values of mass attenuation coefficients $(\mu / \rho)$ ) at diffrent energies 


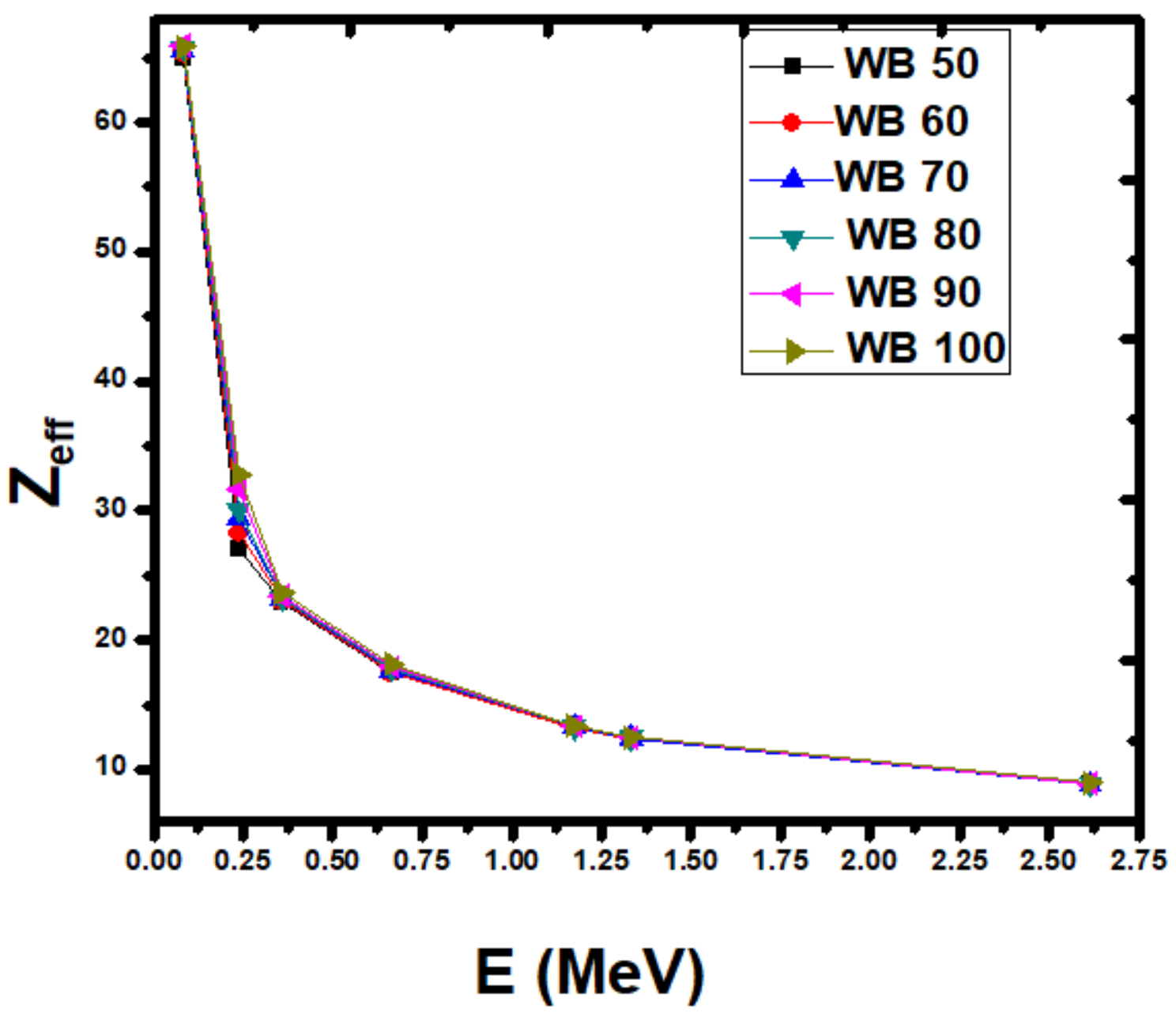

Figure 10

Plot of effective atomic numbers (Zeff) as a function of diffrent energies. 


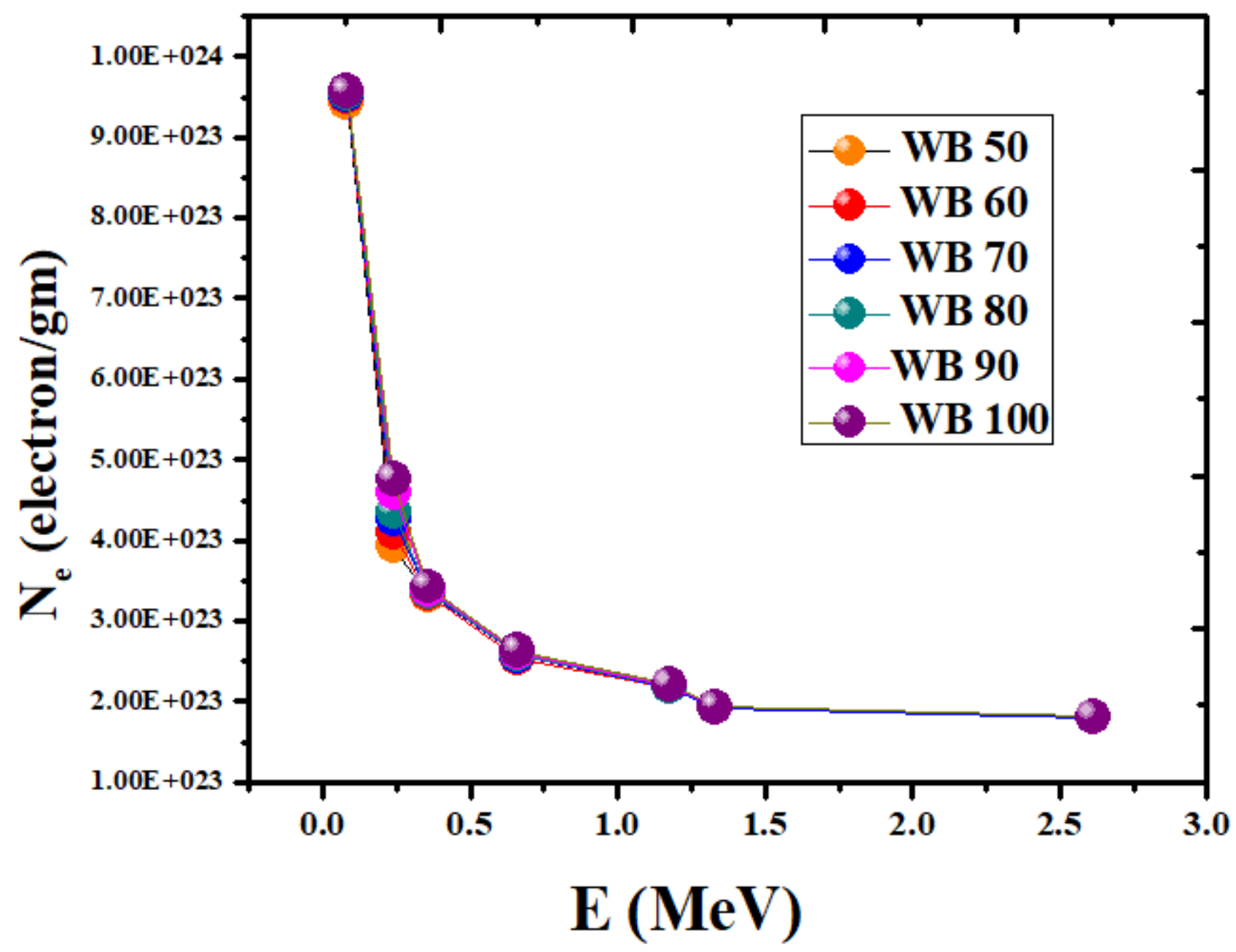

Figure 11

Plot of electron densities $(\mathrm{Ne})$ as a function of diffrent energies. 


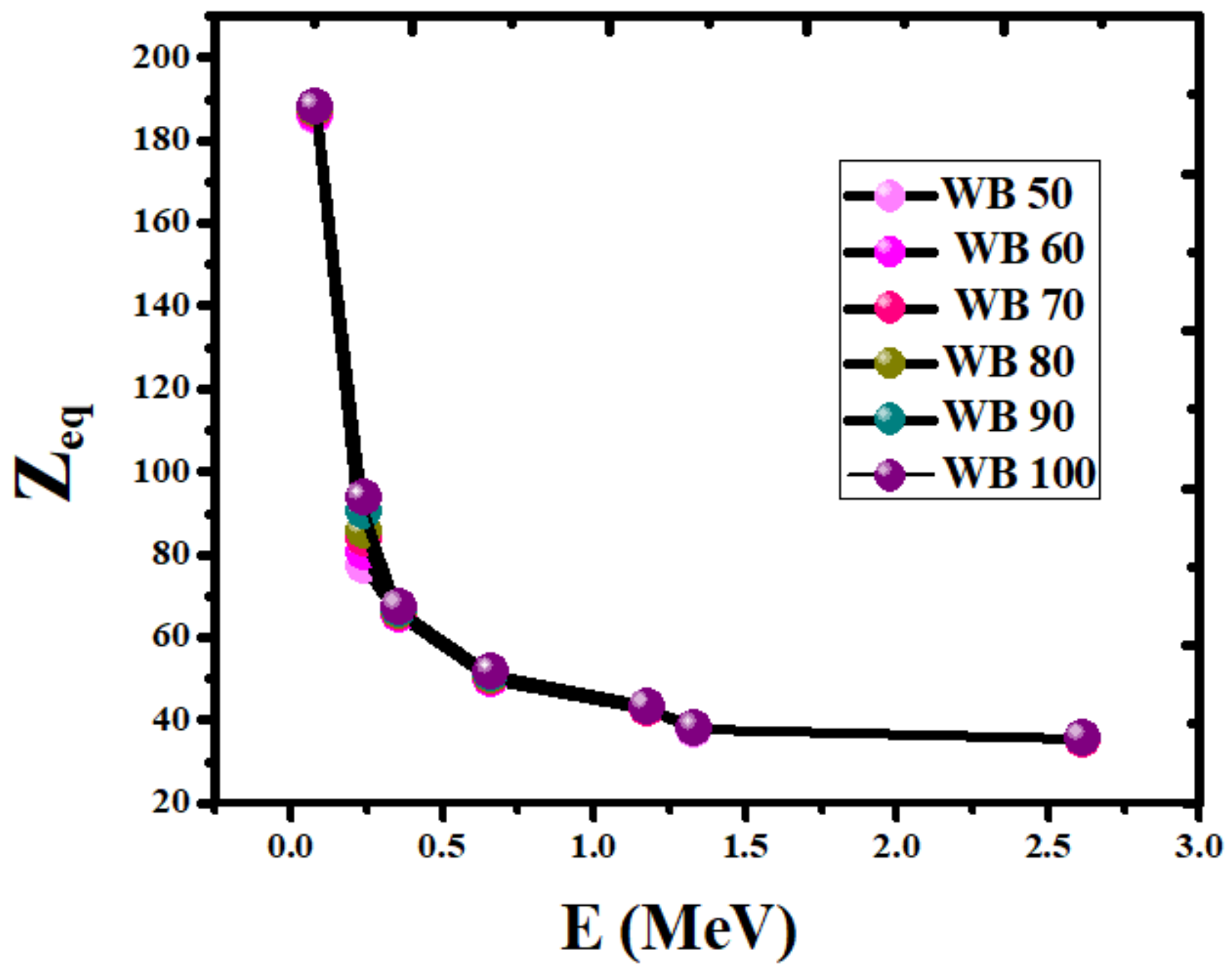

Figure 12

Plot of equavlent atomic numbers (Zeq) as a function of diffrent energies. 


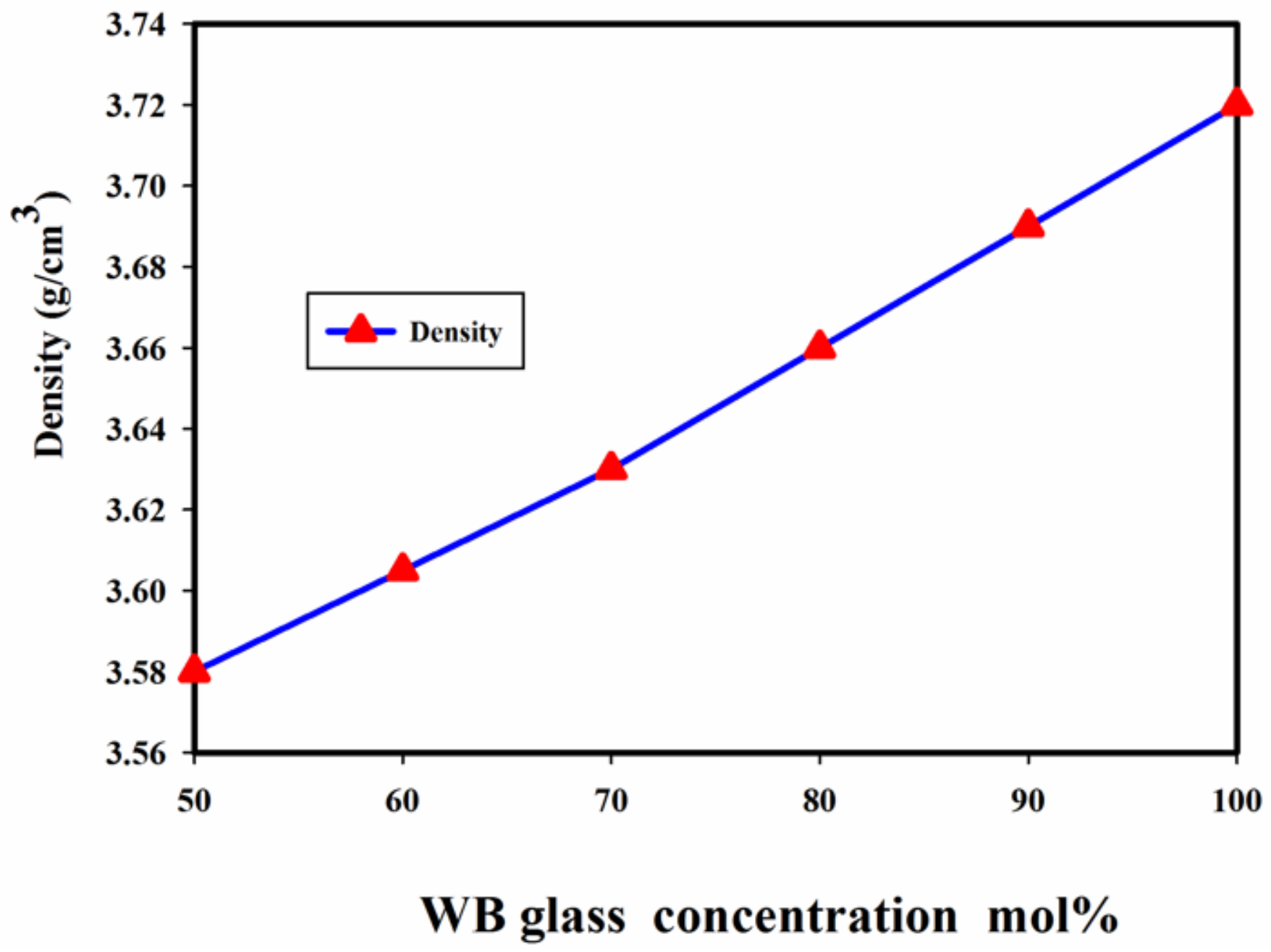

Figure 13

The values of density with different concentration of basalt after heat treatment 


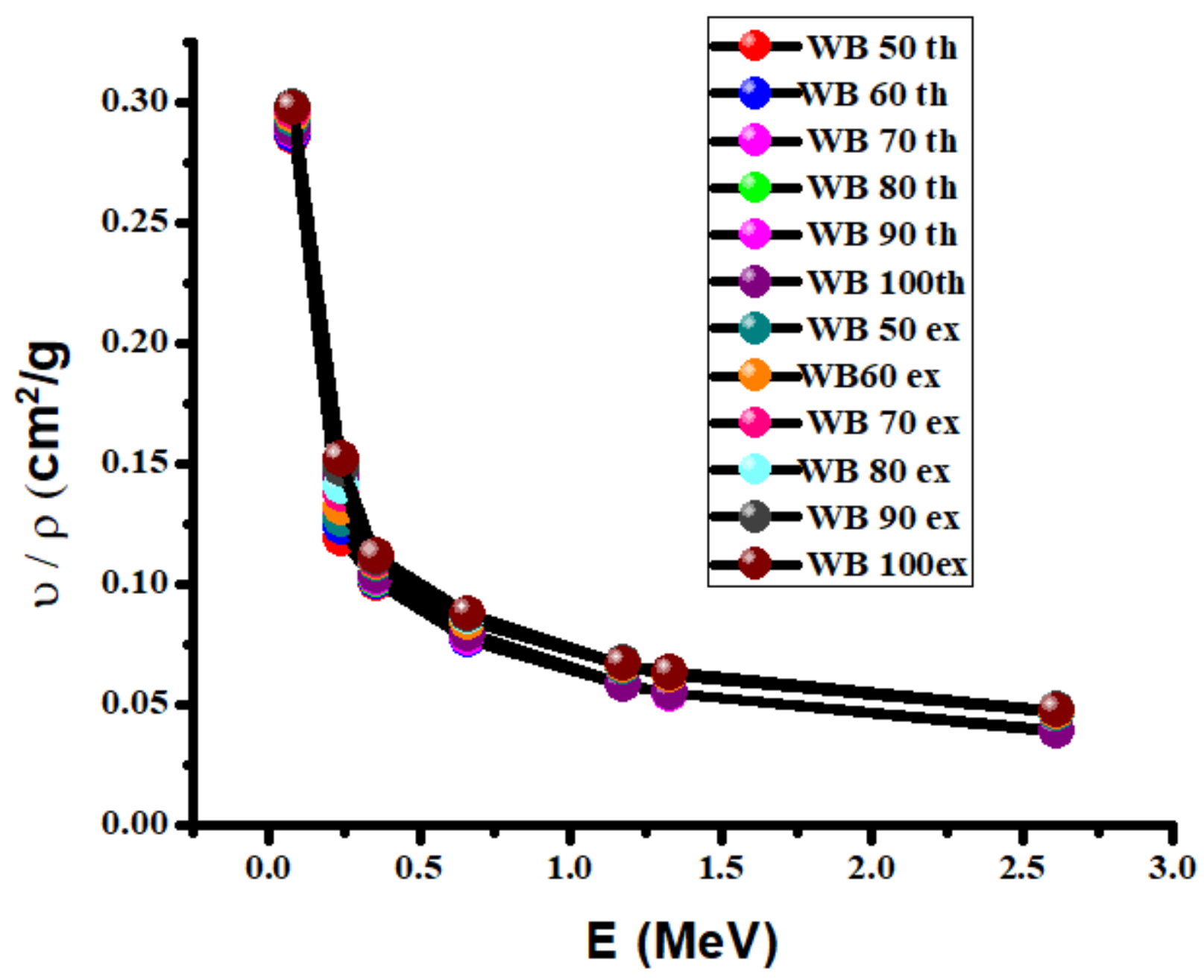

Figure 14

Experimentally measured results and theoretical (XCOM) values of mass attenuation coefficients $(\mu / \rho)$ at different energies of glasses after heat-treatment (1000C0/2hours) 